\title{
OS PERFIS DA LITERATURA DE INTROSPECÇÃO: O DIÁRIO EM VIRGÍLIO FERREIRA E A AUTORIA NA AUTOFICÇÃO
}

Anna Faedrich Martins ${ }^{1}$

RESUMO: O estudo busca, primeiramente, refletir sobre os perfis da literatura de introspecção, dando um enfoque especial para a escrita diarística do autor português Vergílio Ferreira. Depois, intenciona mapear a proposta doubrovskiana de autoficção enquanto variante pós-moderna da autobiografia, a partir da análise da conceitualização do gênero feita por Doubrovsky e daquele que seria considerado o primeiro romance autoficcional - Fils (1977), também escrito pelo teórico francês, em resposta à lacuna existente nos estudos realizados sobre a autobiografia por Philippe Lejeune (Le pacte autobiographique, 1975). Revisaremos o amplo e polêmico debate acerca do neologismo, o diálogo existente entre o conceito original de autoficção e as constantes atualizações de suas formas, presentes na literatura contemporânea, e o ideário incipiente, nos anos 60 , de teorias pós-modernas (principalmente, Michel Foucault). O estudo pretende ampliar o debate existente em língua francesa e trazê-lo para os estudos teóricos e literários do Brasil.

PALAVRAS-CHAVE: Literatura de Introspecção; Diário; Autoficção; Vergílio Ferreira; Serge Doubrovsky.

\section{PROFILES OF INTROSPECTIVE LITERATURE: THE JOURNAL IN VIRGÍLIO FERREIRA AND AUTHORSHIP IN AUTOFICTION}

\begin{abstract}
First of all, this study intends to reflect about the profiles of introspection literature, specially the daily writing of the Portuguese author Vergilio Ferreira. Also, this study intends to analyze Doubrovsky's propose of autofiction as an autobiography post-modern variation. Doubrovsky has created the neologism autofiction and written the first autofictional novel - Fils (1977). He has written about this concept as an answering to Philippe Lejeune's study (Le pacte autobiographique, 1975). We intend to revisit the long and polemic debate about the neologism, the dialog between the original concept and its variations, and the theories post-moderns of sixties (especially Michel Foucault). This study intends to bring this debate to Brazil's studies of theories and literatures.
\end{abstract}

KEYWORDS: Introspection Literature; Diary; Autofiction; Vergílio Ferreira; Serge Doubrovsky.

${ }^{1}$ Professora Substituta de Literatura Brasileira na Universidade do Estado do Rio de Janeiro (UERJ). Doutoranda em Letras - Teoria da Literatura - na Pontifícia Universidade Católica do Rio Grande do Sul (PUCRS) e bolsista do CNPq, sob orientação da profa. Dra. Ana Maria Lisboa de Mello. Realizou Estágio de Doutorado-Sanduíche na Université de la Sorbonne Nouvelle - Paris 3, com bolsa da CAPES (Processo no 851111-0), sob orientação da profa. Dra. Jacqueline Penjon. E-mail: anna.faedrich@gmail.com 


\section{Os perfis da literatura de introspecção: o diário em Vergílio Ferreira}

Viver é estar à espera de alguma coisa, ou seja, inventar o futuro. Será a morte um futuro? Vergílio Ferreira

A literatura de cunho íntimo, confessional e subjetiva, é aquela que mais se aproxima do leitor, pois está centrada no sujeito, fala de um $\boldsymbol{e u}$ que tenta desnudar a sua vida, se revelar, estabelecendo, assim, um elo íntimo entre autor e leitor. As narrativas de introspecção são compostas por diferentes gêneros literários, que muitas vezes mesclam ficção e realidade, entre eles a autobiografia ${ }^{2}$, o romance autobiográfico, a narrativa epistolar, o diário íntimo, o diário ficcional e, recentemente, a autoficção.

Muitos autores utilizam-se dessas estruturas - escrita diarística, epistolar, confessional - como estratégia literária, como é o caso do romance epistolar de Choderlos de Laclos, Relaçoes Perigosas (1782). Segundo Carlos Reis e Ana Cristina Lopes (1994), a narrativa epistolar é uma técnica literária que consiste em desenvolver a história principalmente através de cartas, ou de conjuntos de cartas, normalmente trocadas entre duas ou mais personagens, relatando uma história que se vai configurando pela articulação desses vários testemunhos, embora também sejam usadas entradas de diários e notícias de jornais. O auge de popularidade deste gênero foi no século XVIII, declinando no século XIX. De acordo com o Dicionário Houaiss, o nome "epistolar" vem do latim epistoláris "relativo a carta, epístola". Percebemos, então, que o objetivo desta técnica ao ser criada era dar maior realismo a uma história. Como exemplos de romances epistolares, temos também: Os sofrimentos do jovem Werther, Goethe (1774), Drácula, Bram Stoker (1897) e Gente Pobre, Dostoievski (1846).

Jean Rousset (1962) aponta para o tempo presente das narrativas epistolares, uma vez que as personagens narram suas vidas ao mesmo tempo em que a vivem, observando, também, a exploração da subjetividade na escrita de introspecção realizada através da técnica de troca de cartas:

No romance por cartas, os personagens contam as suas vidas no mesmo tempo em que a vivem; o leitor é tido como um contemporâneo da ação, ele a vive no momento em que ela é vivida e escrita pela personagem [...] As diversas cartas de uma mesma personagem

\footnotetext{
2 Considerando a ideia de Mikhail Bakhtin (1997) de que a autobiografia é um ato literário, ou seja, um ato estetizado, à medida que o autor objetiva o seu Eu e a sua vida num plano artístico.
} 
representarão a inclinação de sua vida interior, à maneira de uma sequência de instantes (ROUSSET, 1962, p. 69-70). ${ }^{3}$

Frédéric Calas (1996, p. 24-39) observa que na comunicação epistolar existe a emergência de dois polos: o remetente/narrador e o destinatário/narratário. Sendo assim, "uma voz face ao silêncio; uma voz face à outra; [destinatário ativo - amante; ou passivo o confidente]; o diálogo de duas vozes; um triângulo de vozes; polifonia - múltiplas vozes".

Já Machado de Assis utiliza a escrita diarística como estratégia em Memorial de Aires e a autobiografia ficcional em Dom Casmurro, por exemplo. Assim como O Diário de Anne Frank é um diário íntimo, escrito por Anne Frank, entre 12 de junho de 1942 a 1 de agosto de 1944, durante a II GM, o Diário de um louco é um diário ficcional, pois Nikolai Gógol utiliza a técnica do diário como estratégia literária. Existe, também, a possibilidade de entrecruzamento desses gêneros, como o faz Lúcio Cardoso em Crônica da Casa Assassinada, romance composto por cartas, testemunhos, confissões, depoimentos, diálogos, livros de memórias e diários. É interessante observar que no diário também não existe a distância entre o presente e o passado, como existe na autobiografia (Cf. PRADO BIEZMA; CASTILLO; PICAZO, 1994, p. 238-239).

Catherine Dumas (1994) enfatiza a problemática literária do diário íntimo observando que na literatura contemporânea a delimitação a respeito da ficcionalidade de cada uma dessas práticas de escritas do eu é um tanto equivocada:

Se é verdade que existe uma problemática literária do diário íntimo, ela torna-se ainda mais flagrante numa contemporaneidade em que o autor, ao escrever um diário, sabe à partida que este será publicado, assumindo a publicidade das suas ditas "confidências" e mesmo da sua publicação ainda em vida (DUMAS, 1994, p. 125-126).

Esse é o caso de Vergílio Ferreira ao escrever Conta-corrente, seu diário pessoal publicado em cinco volumes (Conta-corrente 1, 2, 3, 4 e 5). Ao escrever estes diários, Ferreira registra documentos de uma época e disponibiliza uma leitura de sua ideologia e de sua visão de mundo, muitas vezes já identificada no repertório de suas obras.

André Cabré Rocha diz que "a si próprio o diarista pode confessar o inconfessável", diferente do artista que "elabora, corta, compõe, sublima a verdade" e do epistológrafo que "requinta o que tem para dizer conforme o destinatário a quem confia." (1965, p. 18). Dessa forma, podemos observar que o diário escrito para ser publicado,

3 Tradução nossa. No original: Dans le roman par lettres les personnages disent leur vie en même temps qu'ils la vivent; le lecteur est rendu contemporain de l'action, il la vit dans le moment où elle est vécue et écrite par le personnage [...] Les diverses lettres d'un même personnage représenteront la courbe de sa vie intérieure, à la manière d'une suite d'instantanées. 
como o caso de Conta-corrente, não compactua mais com a ideia de confessar para si o inconfessável, pois a publicação está posta. Com isso, cria-se em Conta-corrente o espaço de comunicação entre o autor e o leitor. Assim, a composição do diário é subjetiva, uma vez que o narrador é também um manipulador, pois dá ênfase para aquilo que lhe convém e coloca a franqueza e a convicção daquilo que é narrado em constante suspeita, evidenciando um discurso que não é inabalável. A presença deste sujeito enunciador é revelada através das escolhas que ele faz ao longo de sua narrativa, iluminando certos pontos e deixando à sombra outros. Portanto, o acesso ao segredo inconfessável, por sua vez, não passa de ilusão: "a convicção inabalável de que o artista tem o segredo disso. Não tem" (FERREIRA, 1982, p. 69).

$\mathrm{Na}$ citação abaixo, o autor escreve que se recusa a dizer algo que sabe, entretanto, a maioria do não-dito no texto não aparece de forma explícita como esta:

Tensão arterial. Dores de cabeça. Impossibilidade de ler, escrever, refletir. Não irei a Salamanca fazer a conferência. O Palma-Ferreira lerá o meu texto. Mas eu não ia 'ler' - iria 'falar'. Sei que me aguentaria. Mas o pânico que me toma sempre ao estar em público (e ao pensar que vou estar) daria um esticão à saúde. Aliás, sei porque se agravou. Não vou dizê-lo. Se bem que, em estado de tensão, as causas e consequências se confundam. (1982, p. 153-154).

Quando o autor escreve consciente da possibilidade de publicação, falamos em uma escrita intencional, ou seja, o escritor escreve com a presença de um leitor implícito; a escrita é direcionada a alguém (interlocutor) que não vai precisar "procurar" esse diário escondido em algum lugar ou abrir o cadeado que o impossibilitaria de lê-lo. A escrita íntima intencional também exige do autor um compromisso estético, deixando de ser um livre fluxo de desabafo para tornar-se uma obra literária: "o diário íntimo de certos autores serve a obra literária a ponto de estes confundirem o questionamento existencial e o questionamento poético, mesmo nas suas considerações mais técnicas” (DUMAS, 1994, p. 126).

Em Conta-corrente, percebemos a intenção deliberada de um exercício literário. Vergílio Ferreira apresenta a preocupação em trabalhar com a palavra e os seus sentidos, com a estruturação do texto, elaborando frases curtas que dão ritmo à leitura. No excerto abaixo, percebemos, numa pequena mostra, o que Ferreira constrói ao longo de sua obra: um texto repleto de metáforas (“como um teatro vazio”) e de poeticidade ("a cor já fria dos dias de Inverno"), utilizando o diário enquanto estratégia literária:

Fomos à praia. Sol quente, água frígida. Pouca gente. E a imagem inquietante de uma praia quase deserta. Como um teatro vazio. As casas 
na colina vão fechando, a esplanada de um café abandonada, a estacaria dos toldos sem panos. No mar a cor já fria dos dias de Inverno. (1982, p. $362)$.

Dumas diz que o diário íntimo é, de algum modo, uma tentativa de o escritor reencontrar o sentido da sua escrita. No diário de Vergílio, percebemos um questionamento das possibilidades de escrita perpassando diversas vezes o texto: "Acusamme de nos livros estar sempre a fazer 'experiências'. Não é isso. Em todo o caso, para a monotonia basta a vida" (1982, p. 363).

O diário íntimo é um dos gêneros da literatura de introspecção, ele é de cunho subjetivo e confessional. Nele estabelece-se o espaço da palavra de um sujeito, que se volta para si mesmo, num mergulho no $\boldsymbol{e u}$, em busca de autoconhecimento através da análise das experiências vividas, ou, também, em busca de alívio, à medida que ele objetiva sua vida num plano artístico. Segundo Catherine Dumas, “o diário íntimo é o crochê; objeto a ritmar uma escrita sem fim, regular, exutório da sensibilidade” (1994, p. 129).

Pensar o diário e a epístola como uma escrita da introspecção nos leva a respostas plausíveis para as perguntas inquietantes que inspecionam o motivo pelo qual as pessoas procuram esse tipo de texto: por que ler um diário? Quais as razões que movem o leitor para a literatura confessional? Seria apenas a curiosidade? Um consolo, talvez? Ou uma identificação com os problemas pessoais do autor? O que levaria uma pessoa a escrever um diário para ser publicado? Poderíamos pensar que, de acordo com o conceito de introspecção, o autor busca na criação literária a emergência em si mesmo, num processo contínuo de autoconhecimento, no qual recria experiências vividas através do desdobramento do $\boldsymbol{e u}$, reconstruindo a si próprio.

Georges Gusdorf, filósofo e epistemólogo francês, afirma que o diário íntimo, enquanto ato de escrita, poderia ter coincidido com o nascimento do texto literário, porém foi no Romantismo que esse gênero foi integrado na literatura, uma vez que é nesse período que a subjetividade ganha valor literário. Dessa forma, Gusdorf demonstra que o diário íntimo manifesta uma atitude antropológica, em que os "escritores do eu" correspondem à problemática existencial encontrada no centro da escrita íntima (GUSDORF apud DUMAS, 1994, p.125).

Essas narrativas de exploração da subjetividade têm em comum a busca do autoconhecimento, o voltar-se para si mesmo, o mergulho no Eu, a análise das experiências vividas por um sujeito. Esse mergulho introspectivo pode ser feito através do próprio autor, das suas experiências vividas e narradas, ou pode ser feito através da subjetividade de 
uma personagem fictícia. Na maioria dos casos de introspecção, quem narra é quem age, isto é, o $\boldsymbol{e u}$ que narra (sujeito) é o $\boldsymbol{e u}$ que age (objeto), independentemente da identidade entre autor e narrador. Assim acontece na literatura confessional: confissões, memórias e diários, e também nas denominadas autoficções.

Para Georges Gusdorf, a literatura do eu é fenomenológica, e não ontológica. Trata do "homem curioso de si e curioso dos outros; um observador mais ou menos imparcial de uma espécie da qual se considera representante” (GUSDORF, 1991, p. 225). Ao centrar no $\boldsymbol{e u}$, o escritor reagrupa os momentos de dispersão da própria vida, para buscar uma nova coerência, para descobrir um sentido ou um motivo da existência, isto é, uma unidade. De acordo com Gusdorf (1991, p. 226), "nunca é somente escrever sobre aquilo que eu sou, mas também sobre aquilo que eu quero ser". Assim, o filósofo acrescenta que quem escreve se aprova ou se desaprova, não é uma testemunha indiferente, e essas motivações, geralmente, não são evidentes para quem escreve.

Outro motivo que move o escritor do eu a escrever sobre si, para Gusdorf, é a descoberta de que a realidade própria é problemática, e, por não se expressar de maneira transparente, leva certas pessoas a investigá-la. São pessoas com tendência à introversão e ao exame de consciência que Gusdorf relaciona com uma não conformidade com o mundo social ao redor; pessoas de um nível cultural bastante elevado; pessoas com um "étonnement d'être", uma inquietude de ser; indivíduos que buscam um sentido à vida, "na contramão do movimento natural da existência”, que levaria para fora, para os outros.

\section{A questão da autoria na autoficção}

O anonimato literário não nos é suportável. Michel Foucault

As teorias das narrativas de introspecção apontaram para a necessidade do estudo da autoficção, enquanto linhagem das narrativas que exploram a subjetividade. O termo autoficção é recente nos estudos críticos e literários feitos no Brasil. Quando comecei a escrever a tese de doutorado sobre o assunto em 2010, havia, ainda, pouco material disponível em língua portuguesa. E isso foi, inclusive, o que me levou a querer estudar mais sobre o assunto e disponibilizar essa discussão na nossa língua. Hoje, já temos excelentes pesquisadores e professores versando e publicando sobre o assunto, como por exemplo, Luciana Hidalgo, Eurídice Figueiredo e Jovita Maria Gerheim Noronha. 
Percebemos que o termo autoficção funciona bem em diferentes campos da arte e em diferentes línguas (no francês, autofiction; no espanhol, autoficción). Podemos falar em filmes, pinturas, quadrinhos, peças teatrais, performances, poemas, contos, minicontos, novelas, romances autoficcionais. O seu uso tem se expandido cada vez mais e será verbete da próxima edição do dicionário Houaiss (o que aponta para a necessidade de inclusão do termo - já tão difundido oralmente - na nossa língua mãe). Talvez, essa expansão exacerbada tenha nos levado à banalização do termo, muito criticada pelo seu próprio criador, Serge Doubrovsky. Tal banalização, por sua vez, leva muitos escritores e críticos à rejeição do uso do termo.

O neologismo autofiction criado por Serge Doubrovsky, em 1977, já não é mais surpresa para ninguém. Para Doubrovsky, a autoficção é "uma variante pós-moderna da autobiografia na medida em que ela não acredita mais numa verdade literal, numa referência indubitável, num discurso histórico coerente e se sabe reconstrução arbitrária e literária de fragmentos esparsos de memória" (apud VILAIN, 2005, p. 212). Tendo em vista essa definição, creio que seja importante, antes mesmo de iniciar uma discussão sobre o que é ou não considerada uma autoficção, entender o ideário filosófico em voga nos anos 70 e pensar o que significa e no que implica dizer que a autoficção é uma variante pósmoderna da autobiografia.

Para isso, é preciso trazer, aqui, nomes que fizeram parte do que Terry Eagleton (2005) denomina a "idade de ouro da teoria cultural", nomes de uma geração mais antiga cuja ambição e originalidade levavam a ideias originais, nomes que articulam noções de sujeito, descontinuidade, escritura, diferença, descentramento, etc. Trata-se, entre outros, de Michel Foucault, Roland Barthes, Gilles Deleuze e Jacques Derrida.

Para adentrar na questão da autoria na autoficção, começo com a provocação de Foucault, feita na entrevista a Christian Delacampagne, publicada em 'Le Monde' (06 de abril de 1980), entrevista concedida sob a condição de ficar anônima, isto é, o jornal não poderia revelar a identidade de Foucault e, sendo assim, o segredo foi mantido até a morte do filósofo. Em “O filósofo mascarado”, Foucault propõe um jogo: “o do 'ano sem nome'. Por um ano publicar-se-iam apenas livros sem o nome do autor". Para Foucault, um autor famoso já não é mais lido, o que é lido é o estrelismo, devido à cultura da sacralização do autor. E, por isso, ele sugere usar o anonimato nesta entrevista, por "saudades do tempo em que eu era absolutamente desconhecido e, portanto, aquilo que dizia tinha alguma possibilidade de ser entendido". Dessa forma, Foucault quer que o livro seja lido por si 
mesmo, recusa a categoria de autor e o gesto biográfico, defende um anonimato rigoroso, o que implicaria, por sua vez, na proibição de utilizar duas vezes o nome de autor.

Em O que é um autor?, Foucault levanta a problematização do sujeito, ao mostrar que a categoria de autor é uma invenção histórica, num certo momento histórico em que foi preciso individuar. Junto à burguesia, aliada ao capitalismo, surgem as noções de propriedade privada, lucro e individualidade. O Romantismo é um momento histórico marcado pelo individualismo, em que se acredita no ser que vai expressar a sua alma profunda, e, a partir dessa noção, o anonimato torna-se impossível:

A noção de autor constitui o momento forte de individualização na história das ideias, dos conhecimentos, das literaturas, na história da filosofia também, e na das ciências. Mesmo hoje, quando se faz a história de um conceito, de um gênero literário ou de um tipo de filosofia, creio que tais unidades continuam a ser consideradas como recortes relativamente fracos, secundários e sobrepostos em relação à unidade primeira, sólida e fundamental, que é a do autor e da obra. (FOUCAULT, 1992, p. 33).

Foucault mostra que nós precisamos nos livrar da expressão, dessa noção de que existe um ser que expressa e que $e n$, enquanto leitor, o entendo. Também a ideia do gênio é uma constituição, não é a existência, mas sim um "sujeito de escrita que está sempre a desaparecer":

Primeiro, pode dizer-se que a escrita de hoje se libertou do tema da expressão: só se refere a si própria, mas não se deixa porém aprisionar na forma da interioridade; identifica-se com a sua própria exterioridade manifesta. [...] Na escrita, não se trata da manifestação ou da exaltação do gesto de escrever, nem da fixação de um sujeito numa linhagem; é uma questão de abertura de um espaço onde o sujeito de escrita está sempre a desaparecer. (FOUCAULT, 1992, p. 35).

Nesse sentido, Roland Barthes afirma que o autor é

uma personagem moderna, produzida sem dúvida por nossa sociedade na medida em que, ao sair da Idade Média, com o empirismo inglês, o racionalismo francês e a fé pessoal da Reforma, ela descobriu o prestígio do indivíduo ou, como se diz mais nobremente, da 'pessoa humana'. Então é lógico que, em matéria de literatura, seja o positivismo, resumo e ponto de chegada da ideologia capitalista, que tenha concedida a maior importância à 'pessoa' do autor. (BARTHES, 2004, p. 58).

É preciso, portanto, ter a distinção clara entre as três instâncias - ser, nome e autor. O ser é o nada, a ausência, aquilo que jamais vamos conhecer, o vazio. A angústia do vazio leva-nos a dar o nome, o nome alivia, controla o vazio. O autor é o nome produzido num momento histórico onde o anonimato não é mais possível, no qual a noção de propriedade faz com que o autor seja um "sujeito proprietário" e, dessa forma, possua um livro tal 
como um objeto e, sendo dono deste livro, passa a ter direitos autorais sobre ele, assim como passa a existir a possibilidade de plágio:

\begin{abstract}
Antes de mais, trata-se de objetos de apropriação; a forma de propriedade de que relevam é de tipo bastante particular; está codificada desde há anos. Importa realçar que esta propriedade foi historicamente segunda em relação ao que poderíamos chamar a apropriação penal. Os textos, os livros, os discursos começaram efetivamente a ter autores (outros que não personagens míticas ou figuras sacralizadas $\mathrm{e}$ sacralizantes) na medida em que o autor se tornou passível de ser punido, isto é, na medida em que os discursos se tornaram transgressores. Na nossa cultura (e, sem dúvida, em muitas outras), o discurso não era, na sua origem, um produto, uma coisa, um bem; era essencialmente um ato - um ato colocado no campo bipolar do sagrado e do profano, do lícito e do ilícito, do religioso e do blasfemo. Historicamente, foi um gesto carregado de riscos antes de ser um bem preso num circuito de propriedades. (FOUCAULT, 1992, p. 47).
\end{abstract}

Foucault diagnostica como funciona esse discurso de verdade. A morte foucaultiana do autor é a percepção de que o autor é uma função, uma palavra inventada para produzir certos efeitos, uma invenção histórica, e não um sujeito absoluto ou uma existência.

[...] a função autor está ligada ao sistema jurídico e institucional que encerra, determina, articula o universo dos discursos: não se exerce uniformemente e da mesma maneira sobre todos os discursos, em todas as épocas e em todas as formas de civilização; não se define pela atribuição espontânea de um discurso ao seu produtor, mas através de uma série de operações específicas e complexas; não reenvia pura e simplesmente para um indivíduo real, podendo dar lugar a vários "eus" em, simultâneo, a várias posições-sujeitos que classes diferentes de indivíduos podem ocupar. (FOUCAULT, 1992, p. 56-57).

Já a morte barthesiana do autor afasta a figura do autor para chamar a atenção para a linguagem e para a impessoalidade da escrita:

Apesar do império do Autor ser ainda muito poderoso (a nova crítica muitas vezes não fez mais do que consolidá-lo), é sabido que há muito certos escritores vem tentando abalá-lo. Na França, Mallarmé, sem dúvida o primeiro, viu e previu em toda a sua amplitude a necessidade de colocar a própria linguagem no lugar daquele que era até então considerado seu proprietário; para ele, como para nós, é a linguagem que fala, não o autor”. (BARTHES, 2004, p. 59).

Dessa forma, percebemos que Doubrovsky define a autoficção como "uma variante pós-moderna da autobiografia”, em meio ao ideário filosófico dos anos 70, pois não acredita na possibilidade de escrita autobiográfica à maneira de Philippe Lejeune, não acredita mais na possibilidade de uma biografia/autobiografia que une vida e obra, apresentando um sujeito absoluto, proprietário de sua vida, de suas decisões e de sua escrita. A proposta doubrovskiana reconhece a ambivalência do sujeito e a mobilidade do vivido, insere o 
discurso do $\boldsymbol{e u}$ no espaço lúdico e transitório, que entrelaça os gêneros referencial e ficcional; verdade e invenção; realidade e imaginação.

Sébastien Hubier ${ }^{4}$ acredita que a autoficção surge como uma solução para tirar a autobiografia de seus impasses. A autoficção, para Hubier, é "uma escritura do fantasma e, a este título, ela coloca em cena o desejo, mais ou menos disfarçado, de seu autor que procura dizer, ao mesmo tempo, todos os eus que o constituem". O estudioso observa que o pacto apropriado para essa variante pós-moderna da autobiografia é o pacto oximoro, que alivia o autor do pacto autobiográfico e da ilusão de autenticidade do relato:

Um dos privilégios da autoficção, fundado sobre um pacto oximoro, seria então a possibilidade de falar, por ela, de si mesmo e dos outros sem nenhuma forma de censura, de entregar todos os segredos de um $e$ u variável, polimorfo, e de se afirmar livre finalmente de ideologias literárias aparentemente defasadas. Ela oferece ao escritor a oportunidade de experimentar a partir de sua vida e de sua ficcionalização, de ser ao mesmo tempo ele mesmo e um outro. ${ }^{5}$

Assim, refletir a questão da autoria na autoficção não é uma questão simplesmente de "dar liberdade para o autor contar mentirinhas", muito menos acreditar que não exista nenhuma forma de censura, como afirma Hubier. Problematizar essa questão é, antes de tudo, reconhecer o incontrolável na escrita, àquilo que foge ao alcance do escritor, uma vez que esse sempre diz mais ou menos o que queria dizer, pois a literatura é linguagem, e a linguagem não dá conta de estruturar o evento (do latim, aquilo que chega), a linguagem é força, e a força não se deixa capturar. $O$ autor trabalha com um conteúdo que não é programável, ele não consegue controlá-lo, nem explicar aquilo que não foi feito para explicar (de acordo com o que dizia Clarice Lispector, "viver ultrapassa qualquer entendimento"). Falamos, então, da experiência do sublime, aquilo que não pode ser reduzido a palavras, o que não podemos expressar; é a experiência do silêncio, "epifania” para James Joyce, "moments of being” para Virgínia Woolf, "spots of time” para William Wordworth.

4Sébastien Hubier (2003) faz um longo estudo sobre as literaturas íntimas (littératures intimes), no qual ele examina o uso singular da primeira pessoa, o eu, nos discursos ditos referenciais e nos discursos literários. Hubier observa que os gêneros que empregam o eu são a autobiografia; as memórias; os diários (journal intime); romance epistolar; romance autobiográfico; crônicas; relatos de viagem; e autoficção. Dessa forma, ele tenta fazer uma divisão entre aqueles gêneros que se pretendem referenciais, ou seja, valorizam a autenticidade do discurso, e os gêneros ficcionais que podem utilizar a forma dos primeiros como intencional estratégia literária. Numa terceira via, Hubier traz à luz os discursos que ficam entre esses dois gêneros, os que estão nos limiares da verdade e da ficção.

${ }^{5}$ No original : L'un des privilèges de l'autofiction, fondé sur un «pacte oxymorique », serait donc qu'il est possible de parler, par elle, de soi-même et des autres sans aucun souci de censure, de livrer tous les secrets d'un moi changeant, polymorphe, et de s'affirmer libre enfin d'idéologies littéraires en apparence dépasées. Elle offre à l'écrivain l'opportunité d'expérimenter à partir de sa vie et de la mise en fiction de celle-ci, d'être tout à la fois et lui-même et un autre. HUBIER, 2003, p. 125. Tradução nossa. 
Jacques Derrida (2009) diz que o grande escritor é aquele que deixa restos, aquele que falha, fracassa, sendo que tudo o que ele diz é um esforço para dizer da melhor maneira aquilo que não diz. O resto pode ser o mais importante do texto e é justamente aquilo que não pode ser ensinado. A crítica de Derrida ao logocentrismo estruturalista, como definida em "Força e Significação" (A escritura e a diferença, 2009), mostra que a escritura é um outro no ser, um excesso, é autônoma em relação à fala; a escritura está para o caos, o acaso, o devir, a força, a diferença, a multiplicidade, o impulso, a mobilidade, o dionisíaco. E, ainda, mostrar que é impossível controlar o incontrolável, "a significação não pode ser contida pela simultaneidade da forma", "o belo não pode ser submetido a esquemas", é preciso, então, compreender a estrutura do porvir, "perder o sentido ganhando-o".

Linguagem que é força, que é vazio, é silêncio, é caos, é o porvir, é o incontrolável, é resto, é excesso. Para Derrida, a "forma fascina quando já não se tem a força de compreender a força no seu interior. Isto é, a força de criar” (DERRIDA, 2009, p. 3). E, segundo Barthes, “uma vez afastado o Autor, a pretensão de 'decifrar' um texto se torna totalmente inútil. Dar ao texto um Autor é impor-lhe um travão, é provê-lo de um significado último, é fechar a escritura" (BARTHES, 2004, p. 63).

A autoficção é a escrita do presente, que não acredita mais na recapitulação histórica e fiel dos acontecimentos, mas sim numa atualização variável da experiência pessoal. Barthes, ao afirmar a morte do autor, fala sobre um novo jeito de conceber a escrita, mostrando que esse afastamento do autor transforma radicalmente o texto moderno, modificando o seu tempo, que, agora, é o tempo presente, tempo que, mais tarde, Doubrovsky vai associar à escrita da autoficção.

O Autor, quando se crê nele, é sempre concebido como o passado de seu livro: o livro e o autor colocam-se por si mesmos numa mesma linha, distribuída como um antes e um depois: considera-se que o Autor nutre o livro, quer dizer que existe antes dele, pensa, sofre, vive por ele; está para sua obra na mesma relação de antecedência que um pai para com o filho. Pelo contrário, o escritor moderno nasce ao mesmo tempo que seu texto; não é, de forma alguma, dotado de um ser que precedesse ou excedesse a sua escritura, não é em nada o sujeito de que o seu livro fosse o predicado; outro tempo não há senão o da enunciação, e todo texto é escrito eternamente aqui e agora. É porque (ou segue-se que) escrever já não pode designar uma operação de registro, de verificação, de representação, de 'pintura' (como diziam os Clássicos), mas sim àquilo que os linguistas, em seguida à filosofia oxfordiana, chamam de performativo [...]. (BARTHES, 2004, p. 61). 
Beatriz Sarlo (2007) observa que os anos 70 e 80 abrem espaço à "guinada subjetiva", ou seja, "uma renovação análoga na sociologia da cultura e nos estudos culturais, em que a identidade dos sujeitos voltou a tomar o lugar ocupado, nos anos 1960, pelas estruturas". Sarlo propõe-se a examinar as razões da revalorização da primeira pessoa como ponto de vista e da confiança no relato da experiência como ícone da Verdade, em que o sujeito narra a sua vida para conservar a lembrança ou, ainda, numa tentativa utópica de entender o passado. Sarlo problematiza a questão, considerando a contradição entre a mobilidade do vivido e a firmeza do discurso.

Se os anos 60 são marcados pela "morte do sujeito", Sarlo aponta para a revalorização desse sujeito a partir dos anos 70:

\begin{abstract}
Quando essa guinada do pensamento contemporâneo parecia completamente estabelecida, há duas décadas, produziu-se no campo dos estudos da memória e da memória coletiva um movimento de restauração da primazia desses sujeitos expulsos durante anos anteriores. Abriu-se um novo capítulo, que poderia se chamar "O sujeito ressuscitado" (SARLO, 2007, p. 30).
\end{abstract}

Sarlo lança mão da crítica da subjetividade e da crítica da representação feitas por Paul de Man e Jacques Derrida. Segundo a teórica, a crítica de Paul de Man à autobiografia provavelmente seja "o ponto mais alto do desconstrutivismo literário", pois, assim como Derrida, nega a possibilidade de um relato autobiográfico cuja relação entre um $e u$ textual e um eu da experiência vivida é verificável. Segundo Man, as autobiografias produzem "a ilusão de uma vida como referência", sendo assim, "a voz da autobiografia é um tropo que faz vezes de sujeito daquilo que narra, mas sem poder garantir a identidade entre sujeito e tropo" (MAN apud SARLO, 2007, p. 31).

Baseada nas reflexões de Man, Sarlo afirma que "as chamadas autobiografias seriam indiferenciáveis da ficção em primeira pessoa”, questionando, assim, a possibilidade de estabelecer um pacto referencial entre autor, narrador e personagem:

Como na ficção em primeira pessoa, tudo o que uma "autobiografia" consegue mostrar é a estrutura especular em que alguém, que se diz chamar eu, toma-se como objeto. Isso quer dizer que esse eu textual põe em cena um eu ausente, e cobre seu rosto com essa máscara (SARLO, 2007, p. 31).

A autoficção é o neologismo necessário para mostrar que não é mais possível acreditar na natureza contratual do gesto biográfico ou na possibilidade de o discurso ser a totalização do singular, conforme critica Foucault, mostrando a tensão de vida e morte presente no texto. O conceito de autoficção caminha ao lado de toda crítica pós-moderna e 
desconstrutivista. Está em acordo com a crítica de Derrida ao logocentrismo, à geometrização e ao fechamento da obra, ao sistema cristalizado que prolonga a tradição metafísica da oposição aparecimento-velamento.

A teoria da autoficção mostra a emergência de uma escritura confessional, o "sujeito ressuscitado" a que Sarlo se refere, as escritas do $\boldsymbol{e u}$, que fazem parte de um sistema confessional instituído na sociedade burguesa, conforme analisa Foucault, onde o $\boldsymbol{e u}$ é guardador de um segredo, uma experiência riquíssima, que merece ser compartilhada e que é preciso confessar. Só que a autoficção surge para mostrar que não acredita mais na possibilidade de uma escrita autobiográfica, verificável e totalizante. A autoficção mostra uma escrita do $\boldsymbol{e u}$ em que o autor não controla o texto, não controla a instabilidade da linguagem que é feita de jogos, é insegura, é abundante, é demasiada. Isso não quer dizer que o autor não importa, que o autor morreu literalmente. É, por isso, que Foucault vai dizer "contenhamos, pois, as lágrimas" (1992, p. 81). Ou seja, não é para levar "ao pé da letra" a morte/apagamento do autor. Trata-se, antes de tudo, de uma crítica às concepções anteriores. Mostra-se um novo ideário filosófico, que analisa e problematiza um binarismo que não é mais possível. "O autor deve apagar-se ou ser apagado em proveito das formas próprias aos discursos", e, na autoficção, aquele que escreve quer que seu livro seja lido como romance, pois o gênero autoficcional, segundo Doubrovsky, confia "a linguagem de uma aventura à aventura da linguagem”.

Foucault permite descobrir o jogo da função autor e analisa a maneira como se exercia tal função no contexto da cultura europeia depois do século XVII. Ele afirma que "definir a maneira como se exerce essa função, em que condições, em que domínio, etc., não quer dizer, convenhamos, que o autor não existe" (p. 81). Assim, o filósofo alerta que não se trata de afirmar que o autor está morto, mas sim de ver de que maneira e segundo que regras se formou e funcionou o conceito de autor. Dessa forma, a emergência do termo e do conceito de autoficção aponta para a crítica da teoria do sujeito e da subjetividade, aponta para uma problematização em relação à figura do autor, à sua sacralização e à insuportabilidade do anonimato literário. 


\section{BIBLIOGRAFIA}

BARTHES, Roland. O rumor da lingua. Prefácio Leyla Perrone-Moisés. Tradução Mario Laranjeira. $2^{a}$ ed. São Paulo: Martins Fontes, 2004.

CALAS, Fréderic. Le roman épistolaire. Paris: Nathan Université, 1996.

DERRIDA, Jacques. A escritura e a diferença. Trad. Maria Beatriz Marques Nizza da Silva ; Pedro Leite Lopes e Pérola de Carvalho. $4^{a}$ ed. São Paulo: Perspectiva, 2009.

DOUBROVSKY, Serge. Fils. Paris: Galilée, 1977. - Autobiographies: de Corneille à Sartre. Paris: PUF, 1988.

DUMAS, Catherine. Diário íntimo e ficção. Contribuição para o estudo do diário íntimo a partir de um 'corpus' português. Colóquio/Letras. 131, Janeiro-Março, p.125-133, 1994.

EAGLETON, T. Depois da teoria: um olhar sobre os estudos culturais e o pós-modernismo. Trad. Maria Lúcia Oliveira. Rio de Janeiro: Civilização Brasileira, 2005.

FERREIRA, Vergílio. Conta-corrente 1. Lisboa: Bertrand, 1982.

FOUCAULT, Michel. O que é um autor? Prefácio de José A. Bragança de Miranda e Antonio Fernando Cascais. $6^{a}$ ed. Lisboa: Vega, 1992.

. "O filósofo mascarado". In: Le Monde, n. 10945, de 06 de abril de 1980: Le Monde-Dimanche, p.p. I e XVII. "Le Philosophe masqué". Tradução: Selvino José Assman. Disponível em: http://www.alfredobraga.pro.br/discussoes/filosofomascarado.html. Acesso em: 19/03/2011.

GUSDORF, Georges. Le principe de l'identité. In: Auto-bio-graphie: Lignes de vie 2, Paris: Éditions Odile Jacob, 1991.

HUBIER, Sébastien. Littératures intimes: Les expressions du moi, de l'autobiographie à l'autofiction. Paris: Armand Colin, 2003.

PRADO BIEZMA, Javier del; CASTILLO, Juan Bravo; PICAZO, María Dolores. Autobiografia y modernidad literaria. Cuenca: Servicio de Publicaciones de la Universidad de Castilla-La Mancha, 1994.

REIS, Carlos; LOPES, Ana Cristina M. Dicionário de narratologia. $4^{a}$ ed. Coimbra: Almedina, 1994.

ROCHA, Andrée Crabbé. A epistolografia em Portugal. Coimbra: Livraria Almedina, 1965.

ROUSSET, Jean. Forme et signification. Essai sur des structures littéraires de Corneille à Claudel. Paris: José Corti, 1962. 
SARLO, Beatriz. Tempo Passado: cultura da memória e guinada subjetiva. Trad. Rosa Freire d’Aguiar. São Paulo: Companhia das Letras; Belo Horizonte: UFMG, 2007.

VILAIN, Philippe. Défense de Narcisse. Paris: Grasset, 2005.

Artigo recebido em 05 de Março de 2012.

Artigo aprovado em 25 de Junho de 2013. 